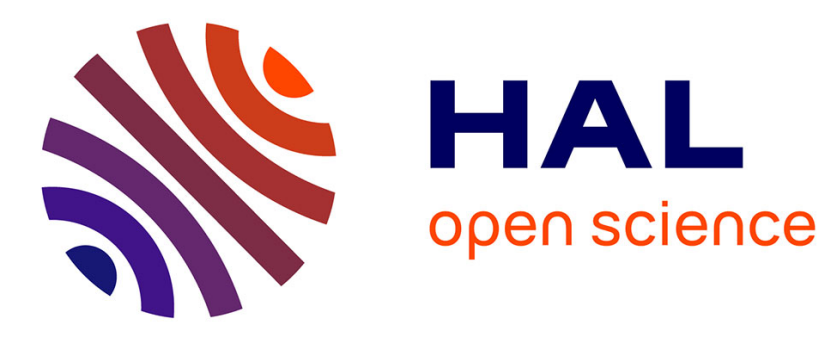

\title{
Fatigue behaviour of non-crimp 3D orthogonal weave and multi-layer plain weave E-glass reinforced composites
}

\author{
Valter Carvelli, Giulia Gramellini, Stepan V. Lomov, Alexander E. \\ Bogdanovich, Dmitri D. Mungalov, Ignaas Verpoest
}

\section{To cite this version:}

Valter Carvelli, Giulia Gramellini, Stepan V. Lomov, Alexander E. Bogdanovich, Dmitri D. Mungalov, et al.. Fatigue behaviour of non-crimp 3D orthogonal weave and multi-layer plain weave E-glass reinforced composites. Composites Science and Technology, 2010, 70 (14), pp.2068. 10.1016/j.compscitech.2010.08.002 . hal-00682265

\section{HAL Id: hal-00682265 https://hal.science/hal-00682265}

Submitted on 24 Mar 2012

HAL is a multi-disciplinary open access archive for the deposit and dissemination of scientific research documents, whether they are published or not. The documents may come from teaching and research institutions in France or abroad, or from public or private research centers.
L'archive ouverte pluridisciplinaire HAL, est destinée au dépôt et à la diffusion de documents scientifiques de niveau recherche, publiés ou non, émanant des établissements d'enseignement et de recherche français ou étrangers, des laboratoires publics ou privés. 


\section{Accepted Manuscript}

Fatigue behaviour of non-crimp 3D orthogonal weave and multi-layer plain weave E-glass reinforced composites

Valter Carvelli, Giulia Gramellini, Stepan V. Lomov, Alexander E.

Bogdanovich, Dmitri D. Mungalov, Ignaas Verpoest

PII:

S0266-3538(10)00298-8

DOI:

10.1016/j.compscitech.2010.08.002

Reference:

CSTE 4783

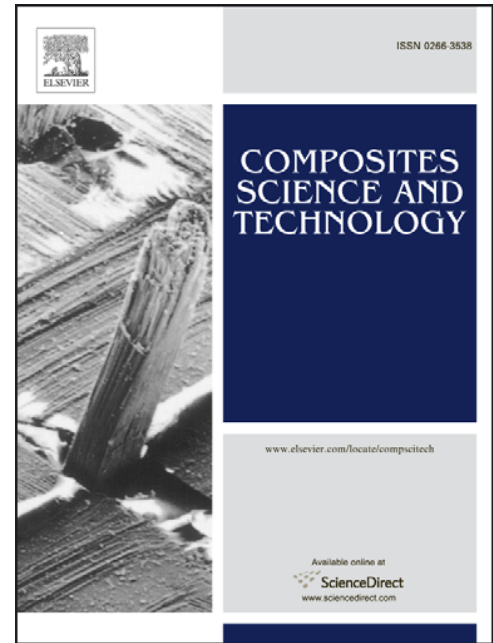

To appear in:

Composites Science and Technology

Received Date:

31 March 2010

Revised Date:

21 July 2010

Accepted Date:

2 August 2010

Please cite this article as: Carvelli, V., Gramellini, G., Lomov, S.V., Bogdanovich, A.E., Mungalov, D.D., Verpoest, I., Fatigue behaviour of non-crimp 3D orthogonal weave and multi-layer plain weave E-glass reinforced composites, Composites Science and Technology (2010), doi: 10.1016/j.compscitech.2010.08.002

This is a PDF file of an unedited manuscript that has been accepted for publication. As a service to our customers we are providing this early version of the manuscript. The manuscript will undergo copyediting, typesetting, and review of the resulting proof before it is published in its final form. Please note that during the production process errors may be discovered which could affect the content, and all legal disclaimers that apply to the journal pertain. 


\title{
FATIGUE BEHAVIOUR OF NON-CRIMP 3D ORTHOGONAL WEAVE AND MULTI-LAYER PLAIN WEAVE E-GLASS REINFORCED COMPOSITES
}

\author{
Valter Carvelli ${ }^{*}$, Giulia Gramellini ${ }^{1}$, Stepan V. Lomov ${ }^{2}$, Alexander E. Bogdanovich ${ }^{3}$, \\ Dmitri D. Mungalov ${ }^{3}$, Ignaas Verpoest ${ }^{2}$ \\ ${ }^{1}$ Department of Structural Engineering, Politecnico di Milano \\ Piazza Leonardo da Vinci 32, 20133 Milano (Italy) \\ ${ }^{2}$ Department of Metallurgy and Materials Engineering, Katholieke Universiteit Leuven \\ Kasteelpark Arenberg, 44, B-3001, Leuven, Belgium \\ ${ }^{3}$ 3TEX Inc., 109 MacKenan Drive, Cary, NC 27511, USA
}

\begin{abstract}
The paper studies tension-tension fatigue behavior of a single-ply non-crimp 3D orthogonal weave Eglass composite and of a laminated composite reinforced with four plies of a standard plain weave fabric. Both composites have same total thickness and very close fiber volume fraction. The paper presents the description of the materials, the results of quasi-static tensile and of tension-tension fatigue tests, including the damage development during fatigue tensile loading. The non-crimp 3D woven fabric composite, loaded in both principal in-plane directions (warp and fill), shows the best quasi-static tensile properties and, when loaded in the fill direction, exhibits much longer fatigue life than its laminated plain weave counterpart. During both quasi-static and fatigue loading, the latest damage initiation is observed for the 3D woven composite in both in-plane directions. The PW laminate develops delamination between the plies for each maximum stress in the cycle considered. Contrary to that, the $3 \mathrm{D}$ composite is not affected by delamination neither under quasi-static nor under fatigue loading conditions.
\end{abstract}

Keywords: (A) Textile composites, (B) Mechanical Properties, Fatigue.

\section{INTRODUCTION}

A key factor driving the increased applications of composites over recent years is the occurrence of new advanced reinforcements developed for fiber reinforced polymer composites, new resin systems and

\footnotetext{
* Corresponding author: tel.: +390223994354 fax: +390223994369 e-mail: valter.carvelli@polimi.it
} 
innovative manufacturing methods. A major driving force has been the development of manufacture and design methods for textile preforms, which permit the production of more sophisticated composites next to the more traditional two-dimensional laminated structures $[1,2]$.

Relatively thick, single layer non-crimp 3D orthogonal woven preforms are gaining fast growing interest in the composites industry. Composites reinforced with single-layer non-crimp 3D woven preforms are nowadays used in a broad range of applications: from personnel and ground vehicle composite armor, to load bearing structures such as bridge decks or windmill blades, marine structures like boats and yachts, and aircraft engines [3, 4, 5, 6, 7]. Efficient modern methods of low-cost manufacturing of non-crimp 3D single-layer preforms, see $[2,4,8]$, increased the interest in the research activities to exploit the full potential of these materials. It is well understood and generally appreciated that 3D woven non-crimp reinforcements provide efficient delamination suppression, markedly improved fracture toughness [9], significantly increased damage tolerance as well as exceptional impact, ballistic and blast performances $[5,6,7]$. In addition, as shown in $[10,11,12,13]$, this kind of $3 \mathrm{D}$ reinforcement provides significantly higher in-plane strength properties than $2 \mathrm{D}$ woven fabric laminates. This is a very distinct positive factor, knowing that 3D interlock woven fabric composites suffer from substantial inherent crimp of the performs and, consequently, show significantly reduced in-plane stiffness and strength even in comparison with 2D plain weave composites $[1,10]$. The difference between composites reinforced with 3D non-crimp orthogonal weaves and 3D interlock weaves is caused, primarily, by the absence of crimp in all inner warp and fill yarn layers. Only minimal deviation from straightness is observed in the surface fill yarn layers due to their interaction with through thickness $(Z)$ yarns. The absence of other types of fiber waviness and misalignment is due to the specialty $3 \mathrm{D}$ orthogonal weaving process and machines used for manufacturing this type of non-crimp fabric, see further information in [2, $4,8]$.

The tensile properties and failure mechanisms of 3D woven composites have been investigated since the mid-1980s. Numerous works have compared the tensile properties of different kind 3D woven composites against two-dimensional plain weave laminates which were, in most of the cases, not equivalent, due to the principal parameters (such as fiber volume fraction and total thickness) were rarely matched, thus not allowing for a meaningful comparison. The exceptions can be found in [10] and in the 
recent publications $[12,13]$. The latter ones present a consistent experimental investigation of the quasistatic in-plane mechanical properties and damage development of 3D orthogonal weave composites. The authors have compared the quasi-static tensile properties and progression of damage of non-crimp 3D orthogonal weave composites to respective properties of the plain weave laminates having nearly equal total thickness and fiber volume fraction. Also importantly, same constituent materials, same resin system, same composite fabrication method and equipment were used in the production of both types of composites.

Fatigue data for non-crimp 3D woven composites are on a high demand by industry. Fatigue of crossply prepreg tape laminates and 2D woven fabric laminates, have been extensively studied (see recent review works $[14,15])$. At the same time, this topic has been barely touched even for the 3D interlock weave composites, see $[16,17,18]$ among few publications. To the best of these authors' knowledge, no fatigue test data are available in literature for non-crimp 3D orthogonal weave composites for either inplane or out-of-plane loading cases. Therefore, this work is viewed as initial effort to generate fatigue test data and get knowledge of fatigue behavior of this class of composites. For such initial effort, in-plane tension-tension fatigue loading in both principal reinforcement directions was chosen. The other fatigue loading cases, like in-plane tension-compression, flexure, in-plane and out-of-plane shear, are of a practical importance and have to be addressed in future work. Fatigue properties of composites reinforced with carbon, S-2 glass and ceramic fiber non-crimp 3D orthogonal woven performs are of a great practical interest too.

The present work aims to provide a contribution to scientific understanding of fatigue behavior of noncrimp 3D woven E-glass composites. One specific material of this kind has been manufactured and studied, side-by-side, with an equivalent thickness and fiber volume fraction plain weave reinforced laminate. The paper presents the characteristics of the two materials, the description of the quasi-static mechanical properties, the fatigue response to tensile-tensile cyclic loading and the transmitting light pictures observation aimed at comparing the damage patterns and their progression caused by cyclic loading at different applied stress amplitudes. 


\section{MATERIALS CHARACTERISTICS}

The materials investigated and compared in this study are (i) composite reinforced with a single-ply non-crimp 3D orthogonal weave E-glass fabric commercialized under trademark $3 \mathrm{WEAVE}^{\circledR}$ (as illustrated in Figure 1a) and (ii) laminated composite reinforced with four plies of plain weave E-glass fabric (shown in Figure 1b). These two materials are termed in the rest of the paper as "3D" and "PW" fabrics and composites, respectively. The $3 \mathrm{D}$ composite is nominally identical to one of the materials (reinforced with "96 oz" fabric) which was characterized in [12, 13] for quasi-static loading, but it belongs to a different batch of production. Due to the possible minor differences between the production batches and the different fiber volume fractions, the quasi-static tensile testing, similar to the reported in $[12,13]$, has been performed for the material studied here. The results of that testing are summarized in the following section.

The non-crimp 3D single-ply orthogonal weave preform has the properties listed in Table 1a. The fiber architecture has 3 warp and 4 fill (a.k.a. "weft") layers. The fabric construction results in $\sim 49 \% / \sim 49 \% / \sim 2 \%$ ratio of the fiber amounts (by volume) in the warp, fill and $\mathrm{Z}$ fiber directions.

The properties of the plain weave preform given in Table $1 \mathrm{~b}$ show slightly unbalanced reinforcement architecture with respect to the total fiber volume content in the warp and weft directions. In order to reach the overall fiber balance in the composite laminate, the fabric layer lay-up $\left(0 / 90 / 90 / 0^{\circ}\right)$ was used when making the four-ply composite. Due to the balanced warp- and weft-directional fiber content in the resulting composite laminate, it was assumed that its in-plane properties are identical, and its mechanical characterization has been performed in one direction only.

The 3D woven fabric was produced by 3 TEX Inc. on their proprietary 3D weaving machine, while the 2D woven fabric was produced on a regular Dornier weaving machine. The fiber material in both cases was PPG Hybon 2022 E-glass. Sample panels of both composites were fabricated in identical laboratory conditions at 3TEX Inc. using Dow Derakane 8084 Epoxy-Vinyl Ester resin. Both single-ply 3D and 4ply PW composites were fabricated in a vacuum bag using Vacuum Assisted Resin Transfer Molding (VARTM) method at room temperature. The 3D and PW composites have (see Table 2) almost identical areal density, very close sample thickness and fiber volume fraction. 


\section{QUASI-STATIC TENSILE TESTS}

The experimental characterization of the composites included quasi-static in-plane tensile loading up to failure with acoustic emission (AE) registration, full-field surface strain mapping (SM), and direct damage observation on backlit samples (AE and SM devices are detailed in $[12,19])$.

The tensile tests were performed using an INSTRON 4505 machine (load cell $100 \mathrm{kN}$ ) setting the crosshead speed of $2 \mathrm{~mm} / \mathrm{min}$. The prismatic samples had width $25 \mathrm{~mm}$ and total length $250 \mathrm{~mm}$. Aluminum tabs $(1.5 \mathrm{~mm}$ thick) were glued in the grip zones with a free length of $150 \mathrm{~mm}$. Test samples were cut out in two principal reinforcement directions determined by the textile preform architecture, i.e. in the warp and fill directions of the 3D composite and in the warp direction of the surface layers in the PW laminate.

The results of the quasi-static tensile tests are summarized in Table 3 for both composite materials and for each loading direction in terms of the Young's modulus (E), ultimate stress $\left(\sigma_{\mathrm{ult}}\right)$ and ultimate strain $\left(\varepsilon_{\mathrm{ult}}\right)$. Each average value and standard deviation in Table 3 was obtained from six tested samples.

The 3D composite exhibits very close Young's moduli in both the warp and fill directions. The difference between elastic modulus of the PW composite and the 3D composite is slightly greater than the respective standard deviations, i.e. it is statistically meaningful. At the same time, as Table 2 shows, the total fiber volume fraction is slightly higher in the case of the PW laminate. We suggest that absence of crimp in the 3D composite vs. the PW reinforced laminate not only compensates for a slightly lower fiber volume fraction in the former one, but results in considerably higher in-plane Young's moduli in both principal directions.

When comparing the ultimate stress and strain values presented in Table 3, a significant difference, much beyond the scatter of experimental data, is observed for the $3 \mathrm{D}$ composite in fill direction vs. PW laminate. The average ultimate stress is $26 \%$ higher and the average ultimate strain is $19 \%$ higher than respective values for the PW laminate. It is also seen in Table 3 that the average ultimate stress of the 3D composite in fill direction is $22 \%$ higher, and the average ultimate strain is $21 \%$ higher than respective values for the same material in warp direction. The $3 \mathrm{D}$ composite shows slightly higher average ultimate stress and nearly the same average ultimate strain in warp direction than the PW counterpart, although the differences are within statistical scatter. 
The trends seen in Table 3 are practically the same as the ones revealed in [12], where same kinds of composites were compared; this makes it unnecessary to repeat the explanations and interpretations presented in the above work. The most important conclusion from both studies, which is essential for this work, is that the studied non-crimp 3D orthogonal weave composite has significantly higher in-plane strength and failure strain in fill direction than in warp direction, and than respective in-plane properties of the studied PW laminate. As suggested in [12], the main reasons for this may be in: (i) the absence of yarn crimp in the $3 \mathrm{D}$ composite and (ii) the lowest fiber damage caused by weaving in the fill direction of $3 \mathrm{D}$ preform, as discussed in $[2,8]$.

\section{TENSILE-TENSILE FATIGUE TESTS}

The response to fatigue loading of the two composite materials was investigated by means of tensiontension cyclic tests. The geometry of the samples is the same as adopted in the quasi-static tensile tests described in the previous section.

\subsection{Experimental Parameters}

Two hydraulic MTS testing machines (load cell $100 \mathrm{kN}$ ) were adopted for the fatigue investigation. Tests were performed under constant stress amplitude, sinusoidal wave-form tensile-tensile loading and assuming the ratio $\mathrm{R}=0.1$ (ratio of the minimum to the maximum stress in the cycle). The stress was evaluated by using the sample cross-sectional area averaged from three measurements. Eight different maximum stress levels were considered, in order to get a complete characterization, from $350 \mathrm{MPa}$ (close to the static failure stress) to the stress level at which complete failure did not occur at least before 5 million cycles $\left(\sigma_{5 \mathrm{~m}}\right)$. Complete failure means separation in two parts of the sample during cyclic loading.

To avoid the influence of tab zones and grip pressure, a cyclic test was considered "valid" if the sample broke at a distance greater than $2 \mathrm{~cm}$ from the tabs. The tests were conducted till three samples showed valid failure for each considered stress level.

To understand the influence of the loading frequency and the temperature on the mechanical response of the two composites in both principal in-plane directions, preliminary DMA (Dynamic Mechanical Analysis) bending tests were performed assuming frequency in the range $0.1 \div 80 \mathrm{~Hz}$ and temperature from the room up to $80^{\circ} \mathrm{C}$ (note that Tg temperature of Derakane 8084 resin used here is $115{ }^{\circ} \mathrm{C}$ ). These 
tests were done with the same number of cycles for all frequencies. The main conclusion of that preliminary study was that below $40^{\circ} \mathrm{C}$ the mechanical response of the materials does not vary for loading frequency between 1 and $30 \mathrm{~Hz}$. Based on this conclusion, further fatigue characterization was performed for several loading frequencies in the range $1 \div 10 \mathrm{~Hz}$, depending on the applied maximum stress and the correct response of the loading device, as detailed in Table 4. The temperature of the samples, measured by a laser thermometer, was not higher than $34^{\circ} \mathrm{C}$ during cyclic loading which in any case is much lower than the resin's Tg.

\subsection{Results}

The response to cyclic tensile loading at different stress levels allows one to deduce the stress level $\sigma_{5 \mathrm{~m}}$. According to the obtained experimental results, the $\sigma_{5 \mathrm{~m}}$ value has been determined as $60 \mathrm{MPa}$ for both cases of the 3D composite in fill direction and the PW laminate, while it was determined as $55 \mathrm{MPa}$ for the $3 \mathrm{D}$ composite in warp direction.

Principal information on the behavior of the composite materials during the cyclic loading is extracted from the observed variation of the shape of the fatigue stress-displacement cycles (further called a "cycle curve" for brevity) during the test. The plot in Figure 2a shows the comparison of some cycle curves of a 3D sample loaded in fill direction with a maximum stress of $60 \mathrm{MPa}\left(\mathrm{e} . \mathrm{g} . \sigma_{5 \mathrm{~m}}\right)$; this is in the range of "high cycle" fatigue. The slope of the cycle curve segment passing through the points of maximum and minimum stress (further called a "cycle slope" for brevity) continuously decreases up to two million cycles (see Figure 2a). Above two million cycles, the slope remains nearly constant. These observations are further confirmed by observing the evolution of the maximum and minimum displacements under increasing number of cycles (see Figure 2b). The reduction of the cycle slope within the initial two million cycles suggests that there is some stiffness degradation of the material caused, in turn, by the damage accumulation during cycling.

Differently to what has been observed at $\sigma_{5 \mathrm{~m}}$ maximum stress level, the evolution of the damage reflects in a continuous decrease of the material stiffness if the maximum stress is in the range of low cycle fatigue. In Figure 3a, some cycles of a 3D sample fatigued in fill direction with a maximum stress of $300 \mathrm{MPa}$ (note that average static strength is $540 \mathrm{MPa}$ ) show a continuous decrease of the cycle slope (respectively, a continuous decrease of the stiffness). The increasing hysteresis area of the cycles and the 
increase of the recorded maximum and minimum displacements (as seen in Figure $3 b$ ) demonstrate a gradual damage development, leading to the ultimate failure of the sample, as illustrated in Figure 4.

The observations described above are valid for the fatigue tests in warp direction of the 3D composite and for the PW laminate.

The fatigue tests performed in a wide stress range enable for depicting a Wöhler-type diagram for both the 3D and PW composites. In Figure 5a, twenty five valid tests in fill direction of the 3D composite (conducted at eight stress levels) are characterized by the variations of maximum stress in the cycle $\left(\sigma_{\max }\right)$ vs. the number of cycles to failure $\mathrm{N}$. The results of twenty seven valid tests in warp direction of the 3D composite (conducted at nine stress levels) and the results of twenty seven valid tests of the PW composite (conducted at eight stress levels) are shown in Figure 5b and Figure 5c, respectively. In each diagram of Figure 5, the respective average static tensile strength (given in Table 3) is also indicated in its correspondence to the extrapolated lowest number of cycles, $\mathrm{N}=1$.

A comparison of the fatigue behavior is detailed in Figure 6 and Table 5. Figure 6 shows the actual "fatigue life" (e.g. number of cycles to failure) for different stress levels. Table 5 presents a comprehensive statistical analysis for each stress level in term of average, standard deviation and covariance of the cycles to failure. The fatigue performance for each stress level of the 3D composite in warp and fill directions is found in exact correspondence with the trends observed in the static tests (see Section 3). Firstly, the PW composite shows, except for $\sigma_{5 \mathrm{~m}}$, significantly worse fatigue performance than the 3D composite tested in fill direction. Secondly, the fill-directional cyclic loading of the 3D composite vs. the PW composite results in the average number of cycles $\sim 51 \%$ higher at $350 \mathrm{MPa}$ stress, $\sim 38 \%$ higher at $150 \mathrm{MPa}$ stress, and $\sim 31 \%$ higher at $70 \mathrm{MPa}$ stress (see Table 5). Further on, the fatigue life of the 3D composite is much longer in fill direction than in warp for all of the applied stress levels. Specifically, the average number of cycles to ultimate failure is $\sim 39 \%$ higher at the stress $350 \mathrm{MPa}, \sim 50 \%$ higher at the stress $150 \mathrm{MPa}$, and $\sim 239 \%$ higher at the stress $70 \mathrm{MPa}$ (Table 5). The PW composite shows a shorter fatigue life vs. the 3D composite in warp direction for stress level $350 \mathrm{MPa}$ (the number of cycles is $\sim 7 \%$ higher for 3D warp). However, for the stress levels $150 \mathrm{MPa}$ and $70 \mathrm{MPa}$ the average numbers of cycles till ultimate failure are higher in the case of the PW composite (by $\sim 9 \%$ and $\sim 160 \%$, respectively, see Figure 6 and Table 5). 
Appropriate fitting equations, applied to the obtained experimental fatigue data, may enable for reliable predictions of the fatigue life for the other stress levels, which were not investigated in the present experimental study. Such a fitting is not aimed at determining the best possible fitting of the obtained experimental data. The diagrams in Figure 5 show the fitting of experimental results by means of three linear segments (for the 3D composite in fill direction the two segments coincide along the same straight line) in three maximum stress ranges: (I) $\sigma_{5 \mathrm{~m}} \div 100 \mathrm{MPa}$, (II) $100 \div 350 \mathrm{MPa}$, (III) $350 \mathrm{MPa} \div \sigma_{\text {ult. This }}$ separation into the three distinct stress ranges correlates with different dominating damage types imparted during the cyclic loading (see further details in section 5 for two stress levels in range (I) and (II)) and has an analogy with the separation of the modes of fatigue damage in [14].

Here, the following fitting by a semi-logarithmic function is used:

$$
\sigma_{\max }=m \log N+C
$$

In eqn. (1), 'm' and 'c' are parameters to be defined by the least squares algorithm. The proposed fitting of the fatigue life over the entire stress range is depicted in Figure 7. The quality of the fitting is related to the coefficient of correlation $\mathrm{R}^{2}$ [20]. Values of $\mathrm{R}^{2}$ close to 1 confirm the reliability of the fitting. All curves in Figure 7 have the coefficient of correlation in the range $0.95 \div 1$.

A comparison of all of the obtained fatigue curves for both composites is presented in Figure 7. The 3D composite fatigued in warp direction exhibits considerably lower fatigue performance in comparison to the PW counterpart for the lower stress levels; both show comparable performance for the intermediate stress levels; the 3D composite shows slightly better performance for the higher stress levels. The difference in the fatigue performance of the 3D composite in the warp and fill directions can be attributed to several reasons. Firstly, there is more of a fiber damage imparted to the warp yarns than to the fill ones during weaving. As hypothesized in [12], this may also be the major reason causing significant difference in the static strength values (and also observed in the static testing of the present work, see Table 3 ). The significance of this effect has been recently confirmed by a comprehensive experimental study performed at 3 TEX for all of the dry E-glass yarns used in the "96 oz" 3D non-crimp orthogonal woven preform. Results of that study will be published elsewhere. Secondly, as illustrated by Figure 1a, in a 3D orthogonal weave composite the presence of $\mathrm{Z}$ yarns creates multiple local "pockets" of pure matrix. It has been discovered earlier for various types of 3D reinforced composites (stitched and Z-pinned [21, 22, 
$23,24,25,26,27,28])$ that through-thickness matrix channels increase local stress concentration and reduce resistance of a composite to initial damage formation. It was also shown experimentally that the presence of such channels may significantly, up to $30 \%$, reduce the in-plain static strength of stitched and Z-pinned composites under tensile and compressive loads. However, there is important difference in our case: as is seen in Figure 1a, there are no through-thickness matrix channels between adjacent fill yarns; instead, there are only relatively thin matrix pockets limited in their thickness to the thickness of the fill yarn layer. Yet, as experimental data show, even such small matrix pockets play significant role in the crack initiation process of 3D woven composites.

It is also worth noting that in the warp-directional loading case $\mathrm{Z}$ yarns are directly subjected to the inplane load, while in the fill-directional loading case they are not loaded directly. Possible effect caused by this aspect is, that the cyclic frictional contact between warp and $\mathrm{Z}$ yarns differs between the two loading cases. Under tensile loading in warp direction, the tensile stress is applied to warp and Z yarns, while the reduction of the sample width takes place due to Poisson's effect. The latter one results in a respective reduction of the distance between adjacent $Z$ and warp yarns. These yarns could get in a contact and, due to both of them are exposed to cyclic tensile stress, their mutual friction effect may become sufficient to significantly reduce the overall fatigue life of the sample. This hypothesis will be the subject of a more indepth investigation in the future work.

\section{FATIGUE DAMAGE DEVELOPMENT}

Damage initiation and development during tensile-tensile fatigue tests have been investigated by means of taking pictures of backlit samples subjected to cyclic loading. The same technique was used in [13], together with microscopical investigation of the cross sections of the damaged samples, and it was shown that for the studied material the backlit damage characterisation is an accurate tool. For fatigue loading the backlit technique has a great advantage: it allows continuous registration of damage development for the same sample, which cannot be done via micrography. Tensile-tensile fatigue tests with accompanied damage observation have been performed for the $3 \mathrm{D}$ and $\mathrm{PW}$ composite materials loaded in the same principal in-plane directions as described before. The following two maximum stress levels were used in the cycle: $\sigma_{5 \mathrm{~m}}$ (stress level contained in range I of the Wöhler diagram, see Figure 7) 
and $200 \mathrm{MPa}$ (in range II of the Wöhler diagram, see Figure 7). Samples fatigued at the stress level $\sigma_{5 \mathrm{~m}}$ have been monitored up to 3 million cycles, while for samples loaded at $200 \mathrm{MPa}$ stress the damage evolution has been monitored till complete failure.

To highlight important peculiarities of the observed local damage patterns and explain the evolution of the local damage events for the 3D and PW composites and different loading directions, pictures of the backlit samples have been taken during loading after different numbers of cycles and were compared in Figure 8 and Figure 9 for maximum stress $\sigma_{5 \mathrm{~m}}$ and $200 \mathrm{MPa}$, respectively (the loading direction is horizontal; vertical direction corresponds to the sample width ). These pictures show a frame of width 25 $\mathrm{mm}$ and length $30 \mathrm{~mm}$ focused on the center of the sample.

First interesting observation is that certain damage was imparted during the first stage of fatigue loading (see Figure 8 after 10,000 cycles). No significant damage has developed if $\sigma_{5 \mathrm{~m}}$ level stress was applied quasi-statically, as indicated by the AE registrations. The comparison of pictures for a fixed number of cycles shows that in the PW laminate there is a higher density of initiated transverse cracks (see Figure 8 after 10,000 cycles). This shows that, similarly to the case of the quasi-static tensile loading, the $3 \mathrm{D}$ composite is less prone to transverse cracking within the yarns or at the yarn-matrix interfaces as compared to the PW composite counterpart.

When increasing the number of cycles, longitudinal cracks appear in the PW composite after approximately 100,000 cycles, while in the 3D composite only transverse cracks with increasing length and density are obseryed at that number of cycles. Longitudinal cracks in both loading directions of the 3D composite are still not visible below 3 million cycles. This observation confirms that, similar to the quasi-static loading case, under the cyclic loading the 3D woven composite is less prone to longitudinal cracking.

The main differences observed for the two loading cases of the 3D composite under maximum stress $\sigma_{5 \mathrm{~m}}$ are:

- for warp-directional loading the existing transverse cracks increase in their length and more significantly in their width;

- for fill-directional loading the transverse cracks increase in number and mutually interconnect. 
- for warp-directional loading the growth of the length of the transverse cracks is faster than that of the transverse cracks produced during the fill-loading.

Pictures in Figure 8 show that for the 3D composite, after 1 million cycles, the damage patterns do not change significantly in regard of transverse cracks density; only few cracks continue to increase in width and length. This observation matches the conclusion deduced in section 4 , where nearly constant cycle slope was observed after approximately same number of cycles has been reached. The PW laminate shows a stable pattern of transverse cracks developed after 1 million cycles. A continuous development of longitudinal cracks gradually increasing their length takes place.

The damage evolution during fatigue tests under maximum stress $200 \mathrm{MPa}$ is illustrated in Figure 9. The damage pattern after the first cycle is similar to that seen in a quasi-static tensile test under the same stress level. In fill-directional fatigue loading of the 3D composite, the transverse cracks saturate after approximately 100 cycles; at that number of cycles the longitudinal cracks and the cracks on $\mathrm{Z}$ yarn surfaces in fill direction are initiated. Further cycling induces a gradual growth and multiplication of the aforementioned longitudinal cracks; the immediate predecessor of ultimate failure is an intensive formation of transverse and longitudinal cracks inside the yarns, which leads to a macro-splitting of 3D woven composite, subsequent fibre breakage in the loading direction, and separation of the sample into parts.

Under warp-directional fatigue loading of the 3D composite, the transversal cracks increase in length and in width faster than it occurs under fill-directional loading. The predecessors of ultimate failure are longitudinal cracks and local debonds around $\mathrm{Z}$ yarns (see Figure 9 after 1,000 cycles). The cycling of the PW laminate causes delamination associated with intensive development of the longitudinal cracks. Moreover, in the PW laminate the longitudinal cracking begins right after the first cycle, while in the 3D composite only few longitudinal cracks had appeared even after 100 cycles of the fatigue loading.

The main conclusions from the damage monitoring during fatigue tests are as follows.

The different slopes of the fatigue curve in range (I) and (II) (see Figure 7) could be related to the different predominant damage mechanism: transverse cracks in range (I) and longitudinal cracks in range (II). 
Inherent crimp of the PW fabric and irregularities of the fabric ply nesting during lamination induce stress concentrations and facilitate damage development during cyclic loading. The damage is initiated earlier during fatigue loading in the PW laminate than in the 3D woven composite.

The absence of crimp and nesting provides better fatigue performances of the $3 \mathrm{D}$ composite (in terms of delayed damage initiation) when tested in both fill and warp directions.

A worse fatigue performance of the 3D composite under warp-directional loading could be attributed to the type of damage and the rate of damage development during fatigue loading. The fabric architecture of the 3D woven preform (see Figure 1a) explains this phenomena: when the load is applied in warp direction (which is, at the same time, the direction of the $\mathrm{Z}$ yarn crowns), both the warp and $\mathrm{Z}$ yarns are loaded in tension. As the consequence, the stress concentration induced by the $\mathrm{Z}$ yarn in its crossover area with the fill yarn becomes significant. This is confirmed by the damage pattern observed during cyclic warp-directional loading of the $3 \mathrm{D}$ composite. Indeed, longitudinal cracks appear in the $\mathrm{Z}$ yarn crossovers (see pictures in Figure 9 at failure), and local debonds start from the crossovers due to relative displacements between adjacent warp and $\mathrm{Z}$ yarns.

It appears that the influence of Z-crowns depends more on the number of cycles than on the applied stress level. In fact, the static strength of the $3 \mathrm{D}$ composite in warp direction is higher than that of the PW laminate, yet the fatigue performance of the 3D composite in warp direction at relatively low stress levels appears to be worse than that of the PW laminate. This behaviour could be the consequence of the frictional forces acting cyclically between warp yarns on one side, and through thickness segments of $\mathrm{Z}$ yarns on the other, as described above.

\section{CONCLUSIONS}

The experimental study presented in this work addressed the fatigue tensile mechanical response of a single-ply non-crimp 3D orthogonal weave E-glass composite and of a laminated composite (reinforced with four plies of a standard plain weave fabric). The tensile-tensile fatigue tests have shown that:

1) The fatigue performance of the PW composite is significantly worse than that of the $3 \mathrm{D}$ composite tested in fill direction for all the studied stress levels, except for the $\sigma_{5 \mathrm{~m}}$ stress level. 
2) The $3 \mathrm{D}$ composite has significantly longer fatigue life when tested in fill direction than when tested in warp direction for all of the applied stress levels.

3) The $3 \mathrm{D}$ composite tested in warp direction has slightly longer fatigue life for the low-cycle fatigue stress range, $\geq 350 \mathrm{MPa}$, but significantly shorter fatigue life for the high-cycle fatigue stress range, $\leq 150 \mathrm{MPa}$, than the PW laminate.

The reliability of these three conclusions, in term of fatigue life, can be assessed by the confidence level index [20]. The confidence levels in Table 6 show that, in strict statistics terms, the hypothesis "the 3D composite in fill direction has a longer fatigue life than the PW laminate" is valid with confidence level $95 \div 99 \%$ (except for $\sigma_{5 \mathrm{~m}}$ ); the hypothesis "the 3D composite in fill direction has a longer fatigue life than the 3D composite in warp direction" is valid with confidence level $98 \div 99 \%$; the hypothesis "the 3D composite in warp direction has a shorter fatigue life than the PW laminate for stress levels $\leq 150 \mathrm{MPa}$ " is valid with confidence level $98 \div 99 \%$.

The damage observations made during tensile-tensile fatigue loading suggest that:

1) When cycling at the stress level $\sigma_{5 \mathrm{~m}}$, longitudinal cracks appear in the PW laminate, while in the 3D composite only transverse cracks develop.

2) The $3 \mathrm{D}$ composite exposed to cyclic maximum stress $\sigma_{5 \mathrm{~m}}$ shows transverse cracks increasing in length and width under warp-directional loading but increasing in number and interconnections under fill-directional loading.

3) Fatigue loading at stress level $200 \mathrm{MPa}$ facilitates in the $3 \mathrm{D}$ composite a faster increase of the length and width of transversal cracks under warp-directional loading than under fill-directional loading.

4) In the PW laminate the longitudinal cracking begins after the first loading cycle with maximum stress of $200 \mathrm{MPa}$, while in the 3D composite only few longitudinal cracks appear even after first hundred cycles.

In general, inherent crimp of the PW fabric and irregularities of the fabric ply nesting during lamination induce local stress concentrations and facilitate earlier damage initiation and development in the PW laminate during cyclic loading in comparison with the $3 \mathrm{D}$ composite. The absence of crimp and 
ply nesting makes, obviously, a strong positive effect on the fatigue behaviour of the non-crimp 3D woven fabric composite in the fill-directional loading case.

\section{Acknowledgements}

The research reported here has been carried out in the framework of the Erasmus Master program of Giulia Gramellini in K.U. Leuven and Politecnico di Milano. The help of laboratory staff of the Department MTM - Bart Pelgrims, Kris van der Staey and Johan Vanhuist - is gratefully acknowledged.

\section{REFERENCES}

1. Tong L, Mouritz AP, Bannister MK. 3D Fibre Reinforced Polymer Composites, Elsevier, 2002.

2. Bogdanovich AE, Mohamed MH. Three-Dimensional Reinforcements for Composites. SAMPE Journal 2009; 45(6): 8-28.

3. Bogdanovich AE. Advancements in manufacturing and applications of 3D woven preforms and composites. Proceeding of the 16th International Conference on Composites Materials (ICCM-16), 2007, Kyoto, Japan.

4. Mohamed MH, Bogdanovich AE, Dickinson LC, Singletary JN, Lienhart RB. A new generation of 3D woven fabric preforms and composites. SAMPE Journal 2001; 37(3): 8-17.

5. LeBlanc J, Shukla A, Rousseau C, Bogdanovich AE. Shock loading of three-dimensional woven composite materials. Composite Structures 2007; 79(3): 344-355.

6. Grogan J, Tekalur SA, Shukla A, Bogdanovich A, Coffelt RA. Ballistic resistance of 2D and 3D woven sandwich composites. Journal of Sandwich Structures and Materials 2007; 9(3): 283-302.

7. Tekalur SA, Bogdanovich AE, Shukla A. Shock loading response of sandwich panels with 3-D woven E-glass composites skins and stitched foam core. Composites Science and Technology 2009; 69(6): 736-753.

8. Mohamed $\mathrm{MH}$, Bogdanovich AE. Comparative analysis of different 3D weaving processes, machines and products. Proceedings of the 17th International Conference on Composite Materials (ICCM-17), 2009, Edinburgh, UK.

9. Tamuzs V, Tarasovs S, Vilks U. Delamination properties of translaminar-reinforced composites. Composites Science and Technology 2003; 63: 1423-1431.

10. Brandt J, Drechsler K, Arendts PJ. Mechanical performance of composites based on various threedimensional woven-fibre performs. Composites Science and Technology 1996; 56: 381-386.

11. Quinn JP, McIhagger AT, McIhagger R. Examination of failure of 3D woven composites. Composite Part A 2008; 39: 273-283. 
12. Lomov SV, Bogdanovich AE, Ivanov DS, Mungalov D, Karahan M, Verpoest I. A comparative study of tensile properties of non-crimp 3D orthogonal weave and multi-layer plain weave E-glass composites. Part 1: materials, methods and principal results. Composite Part A 2009; 40: 1134-1143.

13. Ivanov DS, Lomov SV, Bogdanovich AE, Karahan M, Verpoest I. A comparative study of tensile properties of non-crimp 3D orthogonal weave and multi-layer plain weave E-glass composites. Part 2: comprehensive experimental results. Composite Part A 2009; 40: 1144-1157.

14. Talreja R. Damage and fatigue in composites - A personal account. Composites Science and Technology 2008, 68: 2585-2591.

15. Harris B, editor. Fatigue in composites. Science and technology of the fatigue response of fibrereinforced plastics. Cambridge: Woodhead Publishing Ltd, 2003.

16. Rudov-Clark S, Mouritz AP. Tensile fatigue properties of a 3D orthogonal woven composite. Composites Part A 2008; 39: 1018-1024.

17. Mouritz AP. Tensile fatigue properties of 3D composites with through-thickness reinforcement. Composites Science and Technology 2008; 68: 2503-2510.

18. Gude M, Hufenbach W, Koch I. Damage evolution of novel 3D textile-reinforced composites under fatigue loading conditions. Composites Science and Technology 2010; 70: 186-192.

19. Lomov SV, Ivanov DS, Truong TC, Verpoest I, Baudry F, Vanden Bosche K, Xie H. Experimental methodology of study of damage initiation and development in textile composites in uniaxial tensile test. Composites Science and Technology 2008; 68: 2340-2349.

20. Bain, L., Engelhardt, M., "Introduction to probability and mathematical statistics", Pws-Kent Publishing Company Boston.

21. Dransfield K, Bailie C, Mai YW. Improving the delamination resistance of CFRP by stitching - a review. Composites Science and Technology 1994; 50: 305-317.

22. Mouritz AP, Leong KH, Herszberg I. A review of the effect of stitching on the in-plane mechanical properties of fibre-reinforced polymer composites. Composites Part A 1997; 28: 979-991.

23. Steeves CA. Mechanics of failure in composite structures. Ph.D. thesis, Engineering Department, Cambridge University, U.K., 2001.

24. Steeves CA, Fleck NA. In-plane properties of composite laminates with through-thickness pin reinforcement. International Journal of Solids and Structures 2006; 43: 3197-3212.

25. Partridge IK, Cartié DDR, Bonnington T. Manufacture and performance of z-pinned composites. In: Advanced polymeric materials: structure - property relationships. CRC, 2003: 98-137.

26. Chang P, Mouritz AP, Cox BN. Properties and failure mechanisms of z-pinned laminates in monotonic and cyclic tension. Composites Part A 2006; 37: 1501-1513. 
27. Mouritz AP. Compression properties of z-pinned composite laminates. Composites Science and Technology 2007; 67: 3110-3120.

28. Chang P, Mouritz AP, Cox BN. Flexural properties of z-pinned laminates. Composites Part A 2007; 38: $244-251$.

\section{LIST OF FIGURE CAPTIONS}

Figure 1. Internal architecture of the: (a) non-crimp 3D orthogonal weave single-ply preform (fill yarns on the surface, warp yarns underneath them, and Z-crowns oriented in warp direction over fill yarns); (b) 2D plain weave fabric.

Figure 2. 3D composite loaded in fill direction, max stress $60 \mathrm{MPa}$ : (a) some stress vs. displacement curves; (b) maximum and minimum stress and displacement vs. number of cycles.

Figure 3. 3D composite loaded in fill direction, max stress $300 \mathrm{MPa}$ : (a) some stress vs. displacement curves; (b) maximum and minimum stress and displacement vs. number of cycles.

Figure 4. 3D composite loaded in fill direction, max stress $300 \mathrm{MPa}$ : fatigue failure of a sample.

Figure 5. Maximum stress $\sigma \mu \alpha \xi$ vs. number of cycles to failure $\mathrm{N}$ for: (a) 3D composite loaded in fill direction; (b) 3D composite loaded in warp direction; (c) PW laminate. (' $\rightarrow$ ' means no failure).

Figure 6. Comparison of the fatigue life at different maximum stress levels: (a) $350 \mathrm{MPa}$, (b) $150 \mathrm{MPa}$ and (c) $70 \mathrm{MPa}$. Vertical lines indicate average fatigue life.

Figure 7. Fitting and comparison of the fatigue life curves.

Figure 8. Damage development during fatigue loading for $\sigma \mu \alpha \xi=\sigma 5 \mu$.

Figure 9. Damage development during fatigue loading for $\sigma \mu \alpha \xi=200 \mathrm{MPa}$.

\section{LIST OF TABLE CAPTIONS}

Table 1. Properties of the preforms: (a) 3D and (b) PW.

Table 2. Properties of 3D and PW composites ( \pm means standard deviation).

Table 3. Average values and standard deviations of the quasi-static mechanical properties.

Table 4. Frequency of the cyclic loading adopted for the fatigue tests at different stress levels.

Table 5. Statistical parameters of the fatigue life at the different stress levels.

Table 6. Confidence levels for three hypotheses ('>' means longer fatigue life, ' $<$ ' means shorter fatigue life). 


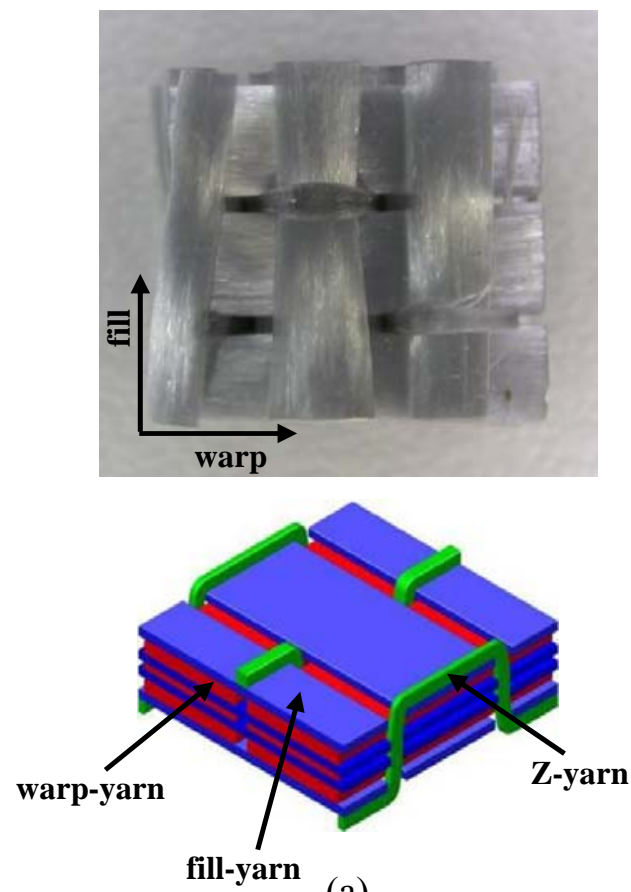

(a)
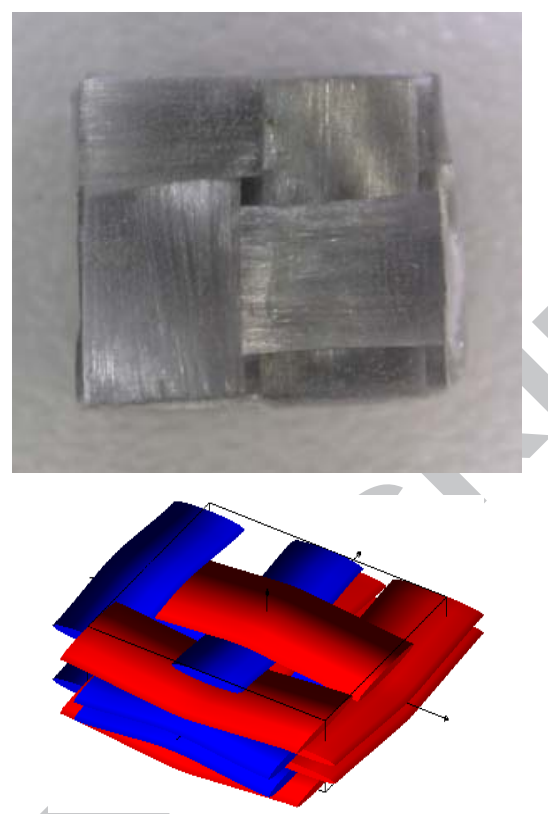

(b)

Figure 1. Internal architecture of the: (a) non-crimp 3D orthogonal weave single-ply preform (fill yarns on the surface, warp yarns underneath them, and Z-crowns oriented in warp direction over fill yarns); (b) 2D plain weave fabric.

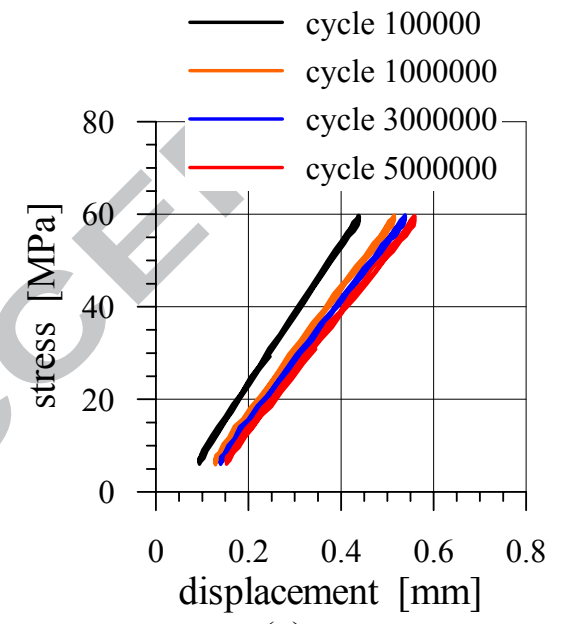

(a)

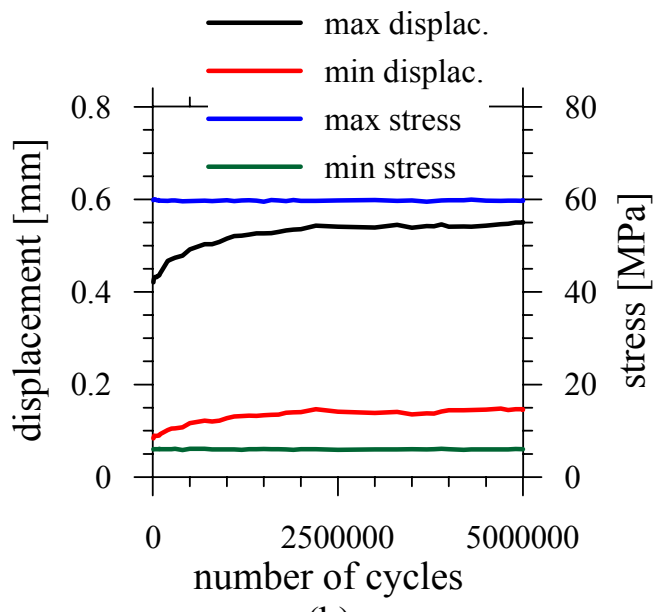

(b)

Figure 2. 3D composite loaded in fill direction, max stress $60 \mathrm{MPa}$ : (a) some stress vs. displacement curves; (b) maximum and minimum stress and displacement vs. number of cycles. 


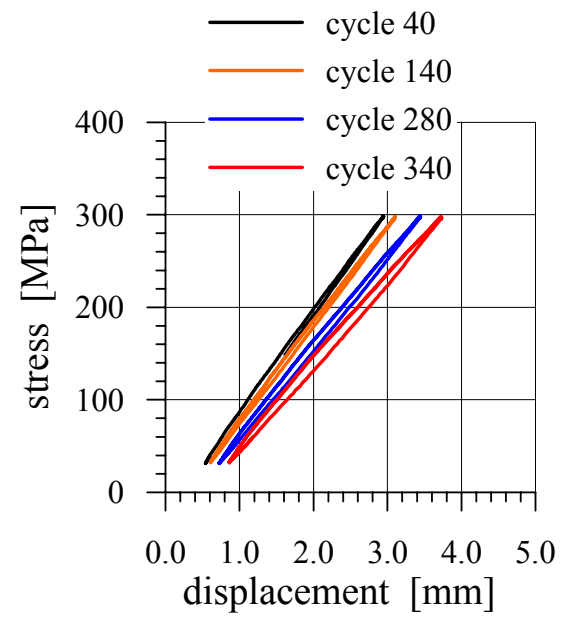

(a)

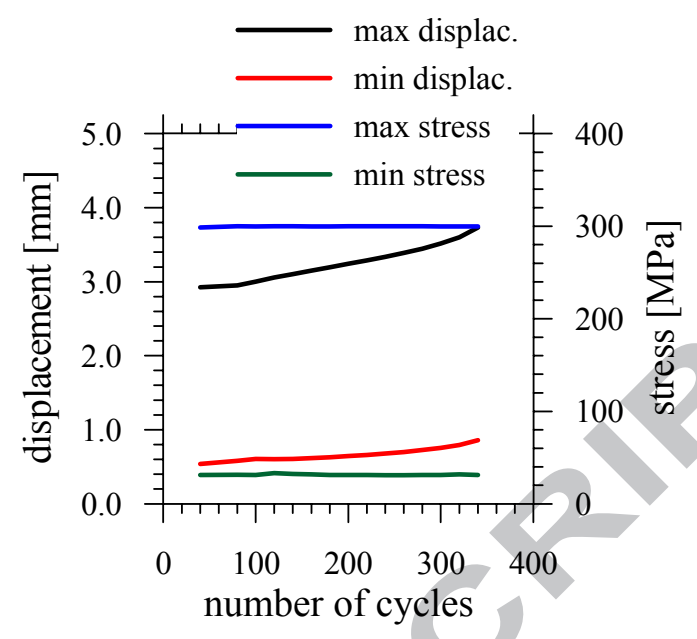

(b)

Figure 3. 3D composite loaded in fill direction, max stress 300 MPa: (a) some stress vs. displacement curves; (b) maximum and minimum stress and displacement vs. number of cycles.

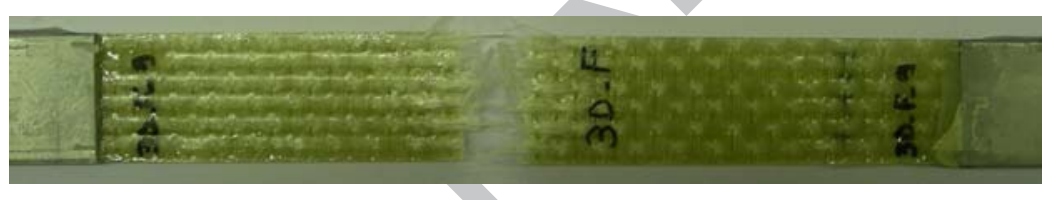

Figure 4. 3D composite loaded in fill direction, max stress $300 \mathrm{MPa}$ : fatigue failure of a sample.

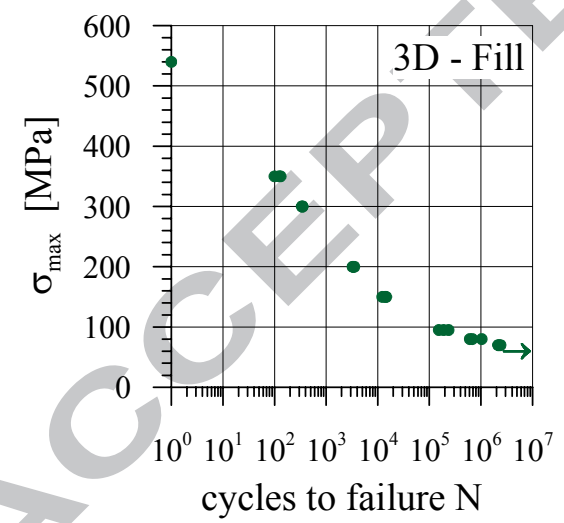

(a)

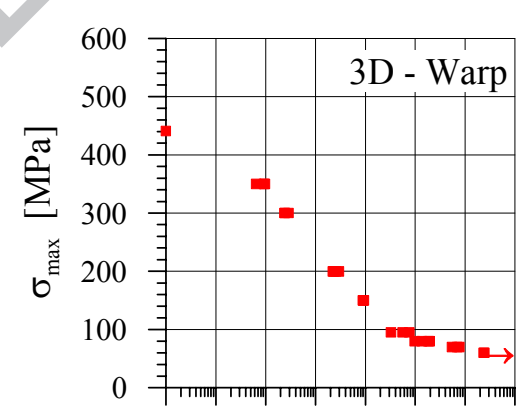

$10^{0} 10^{1} 10^{2} 10^{3} 10^{4} 10^{5} 10^{6} 10^{7}$ cycles to failure $\mathrm{N}$

(b)

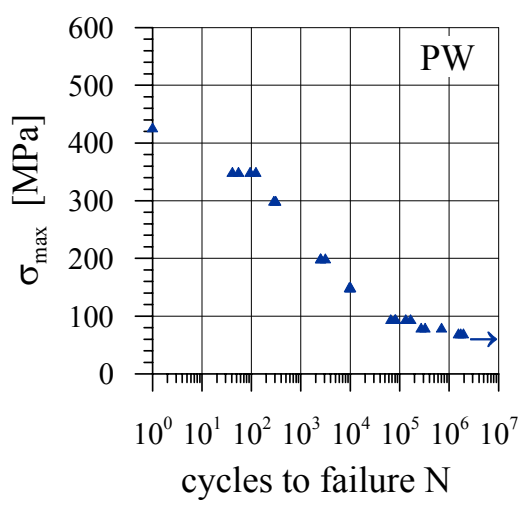

(c)

Figure 5. Maximum stress $\sigma_{\max }$ vs. number of cycles to failure $\mathbf{N}$ for: (a) 3D composite loaded in fill direction; (b) 3D composite loaded in warp direction; (c) PW laminate. (' $\rightarrow$ ' means no failure). 


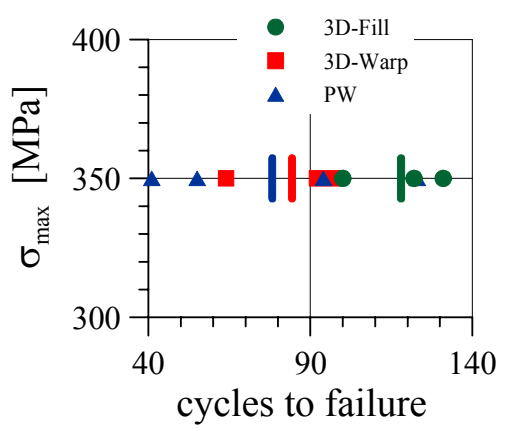

(a)

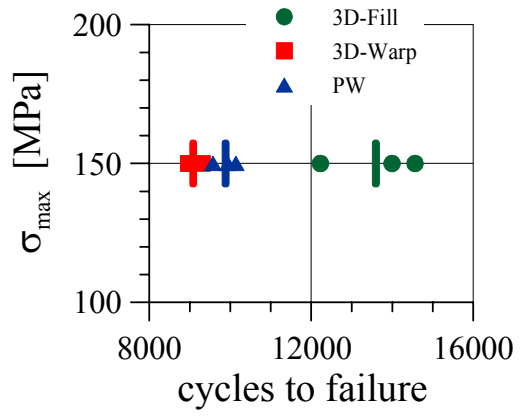

(b)

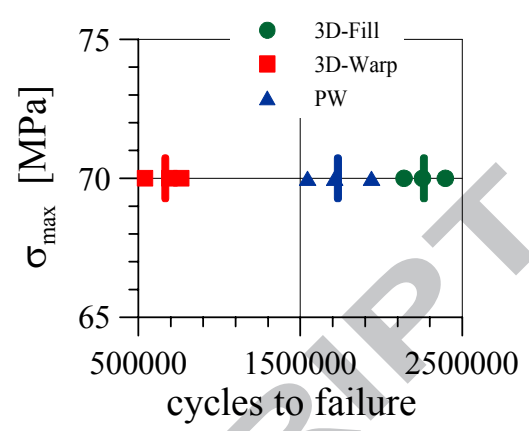

(c)

Figure 6. Comparison of the fatigue life at different maximum stress levels: (a) $350 \mathrm{MPa}$, (b) 150 MPa and (c) 70 MPa. Vertical lines indicate average fatigue life.

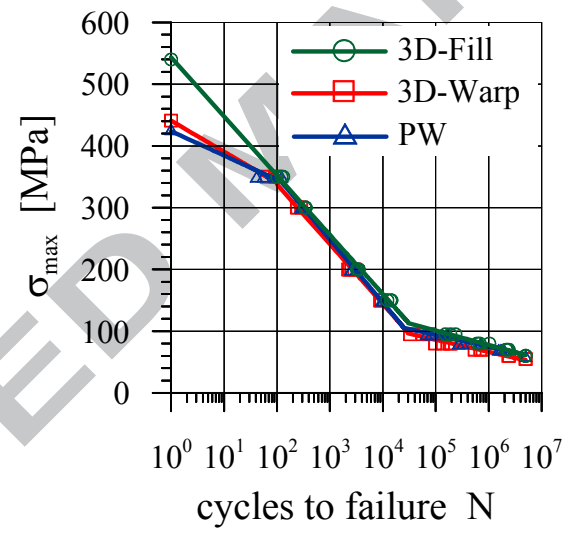

Figure 7. Fitting and comparison of the fatigue life curves. 


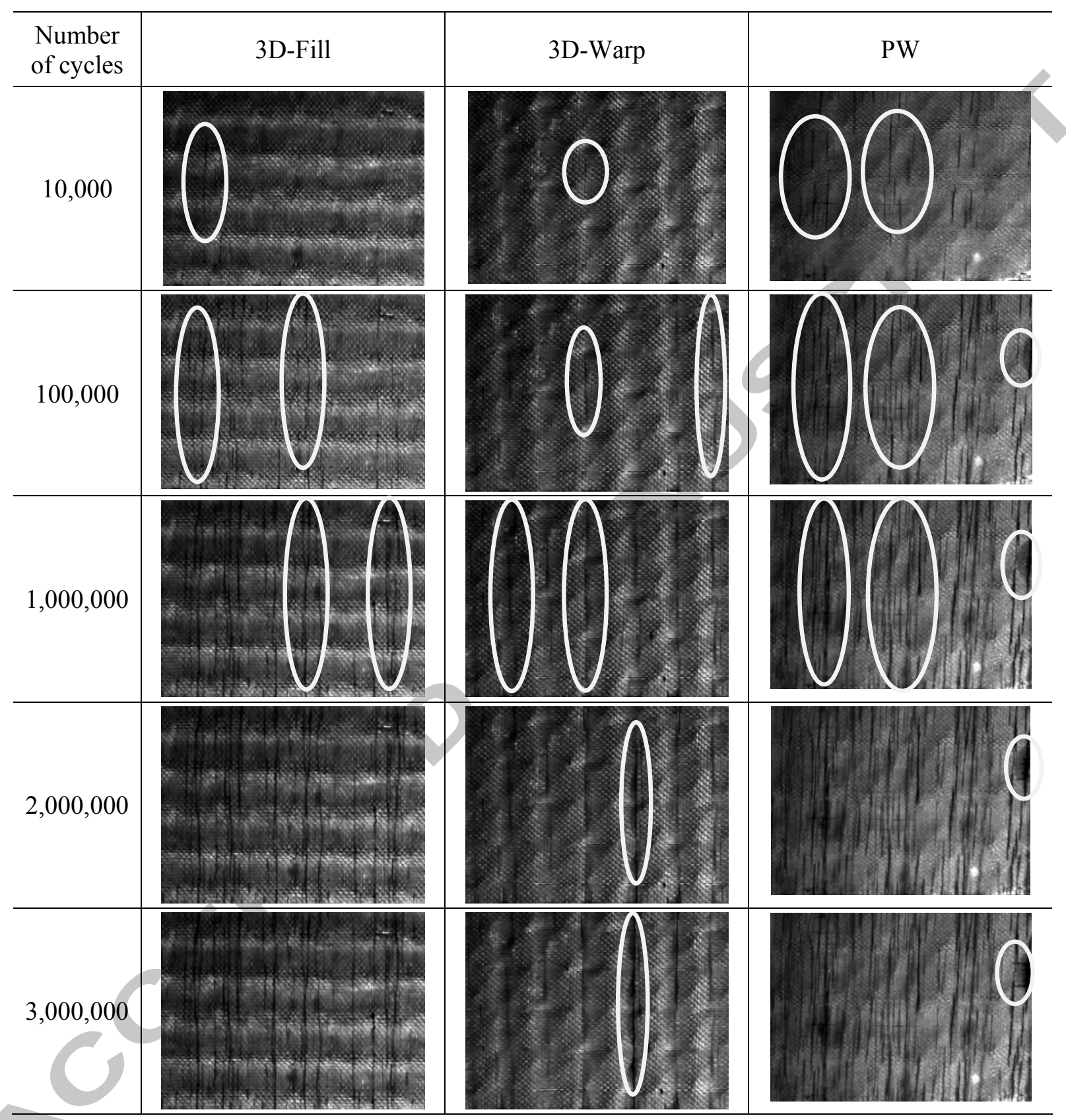

Figure 8. Damage development during fatigue loading for $\sigma_{\max }=\sigma_{5 \mathrm{~m}}$. 


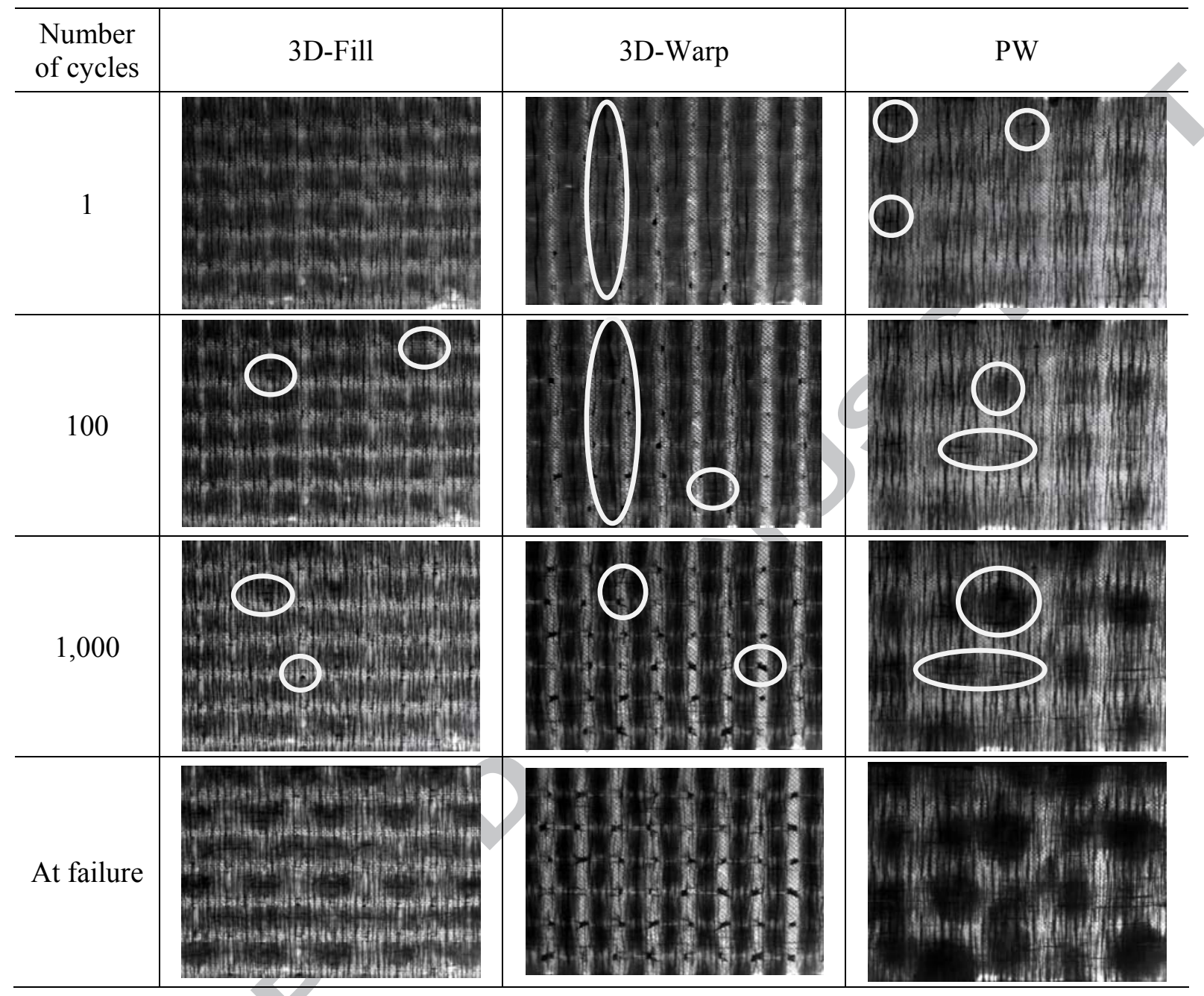

Figure 9. Damage development during fatigue loading for $\sigma_{\max }=200 \mathrm{MPa}$. 


\begin{tabular}{cl|c}
\hline \multicolumn{2}{c}{ 3D non-crimp woven preform } \\
\hline \multirow{2}{*}{} & Fabric plies & 1 \\
\cline { 2 - 3 } & Areal density $\left[\mathrm{g} / \mathrm{m}^{2}\right]$ & 3255 \\
\hline Warp & Insertion density [ends/cm] & 2.76 \\
layer & Top and bottom layer yarns [tex] & 2275 \\
& Middle layer yarns [tex] & 1100 \\
\hline Weft & Insertion density [picks/cm] & 2.64 \\
layer & Yarns [tex] & 1470 \\
\hline Z-yarns & Insertion density [ends/cm] & 2.76 \\
& Yarns [tex] & 1800 \\
\hline
\end{tabular}

(a)

\begin{tabular}{l|c}
\hline \multicolumn{2}{c}{ Plain weave preform } \\
\hline Fabric plies & 4 \\
\hline Areal density $\left[\mathrm{g} / \mathrm{m}^{2}\right]$ & 3260 \\
\hline Ply insertion density: Warp [ends/cm] & 1.95 \\
Weft [picks/cm] & 1.6 \\
\hline Warp and Weft Yarns [tex] & 2275 \\
\hline
\end{tabular}

(b)

Table 1. Properties of the preforms: (a) 3D and (b) PW.

\begin{tabular}{lcc}
\hline & $3 \mathrm{D}$ & $\mathrm{PW}$ \\
\cline { 2 - 3 } Panels thickness $[\mathrm{mm}]$ & $2.58 \pm 0.05$ & $2.57 \pm 0.09$ \\
Fiber volume fraction $[\%]$ & $53.22 \pm 0.63$ & $54.42 \pm 0.65$ \\
\hline
\end{tabular}

Table 2. Properties of 3D and PW composites ( \pm means standard deviation).

\begin{tabular}{cccc}
\hline & $\begin{array}{c}\mathrm{E} \\
{[\mathrm{GPa}]}\end{array}$ & $\begin{array}{c}\sigma_{\mathrm{ult}} \\
{[\mathrm{MPa}]}\end{array}$ & $\begin{array}{c}\varepsilon_{\mathrm{ult}} \\
{[\%]}\end{array}$ \\
\hline 3D-Fill & $26,34 \pm 0.63$ & $540 \pm 20$ & $2,92 \pm 0.05$ \\
3D-Warp & $26,39 \pm 0.76$ & $441 \pm 26$ & $2,41 \pm 0.13$ \\
PW & $24,68 \pm 1.51$ & $427 \pm 23$ & $2,45 \pm 0.18$ \\
\hline
\end{tabular}

Table 3. Average values and standard deviations of the quasi-static mechanical properties.

\begin{tabular}{lccccc}
\hline Maximum Stress [MPa] & 350 & 300 & 200 & 150 & $\leq 95$ \\
Frequency [Hz] & 1 & 2 & 4 & 8 & 10 \\
\hline
\end{tabular}

Table 4. Frequency of the cyclic loading adopted for the fatigue tests at different stress levels. 


\begin{tabular}{|c|c|c|c|c|c|c|c|c|c|}
\hline \multirow{2}{*}{$\begin{array}{c}\text { Stress level } \\
{[\mathrm{MPa}]}\end{array}$} & \multicolumn{3}{|c|}{ 3D-Fill } & \multicolumn{3}{|c|}{ 3D-Warp } & \multicolumn{3}{|c|}{ PW } \\
\hline & Average & Stand. Dev. & Covariance & Average & Stand. Dev. & Covariance & Average & Stand. Dev. & Covariance \\
\hline 55 & & & & $5,000,000$ & $\mathrm{n} / \mathrm{a}$ & $\mathrm{n} / \mathrm{a}$ & & & \\
\hline 60 & $5,000,000$ & $\mathrm{n} / \mathrm{a}$ & $\mathrm{n} / \mathrm{a}$ & $2,393,181$ & 33,563 & $1.4 \%$ & $5,000,000$ & $\mathrm{n} / \mathrm{a}$ & $\mathrm{n} / \mathrm{a}$ \\
\hline 70 & $2,263,028$ & 104,676 & $4.6 \%$ & 666,110 & 93,163 & $14.0 \%$ & $1,731,774$ & 162,194 & $9.4 \%$ \\
\hline 80 & 771,452 & 184,724 & $23.9 \%$ & 153,056 & 38,828 & $25.4 \%$ & 433,181 & 190,699 & $44.0 \%$ \\
\hline 95 & 192,313 & 34,368 & $17.9 \%$ & 55,018 & 17,772 & $32.3 \%$ & 105,785 & 37,825 & $35.8 \%$ \\
\hline 150 & 13,595 & 995 & $7.3 \%$ & 9,083 & 164 & $1.8 \%$ & 9,883 & 233 & $2.4 \%$ \\
\hline 200 & 3,372 & 118 & $3.5 \%$ & 2,506 & 268 & $10.7 \%$ & 2,723 & 292 & $10.7 \%$ \\
\hline 300 & 344 & 6 & $1.7 \%$ & 256 & 22 & $8.4 \%$ & 299 & 11 & $3.6 \%$ \\
\hline 350 & 118 & 13 & $11.1 \%$ & 84 & 15 & $17.2 \%$ & 78 & 32 & $41.3 \%$ \\
\hline
\end{tabular}

Table 5. Statistical parameters of the fatigue life at the different stress levels.

\begin{tabular}{c|c|c|c}
\hline \multirow{2}{*}{$\begin{array}{c}\text { Stress level } \\
{[\mathrm{MPa}]}\end{array}$} & \multicolumn{3}{|c}{ Confidence Level for a hypothesis } \\
\hline 70 & 3D-Fill > PW & 3D-Fill > 3D-Warp & 3D-Warp < PW \\
80 & $99.75 \%$ & $100.00 \%$ & $99.99 \%$ \\
95 & $96.08 \%$ & $99.97 \%$ & $98.72 \%$ \\
150 & $99.28 \%$ & $99.99 \%$ & $98.81 \%$ \\
200 & $99.20 \%$ & $99.97 \%$ & $99.77 \%$ \\
300 & $99.93 \%$ & $99.89 \%$ & $82.80 \%$ \\
350 & $95.24 \%$ & $99.95 \%$ & $98.64 \%$ \\
\hline
\end{tabular}

Table 6. Confidence levels for three hypotheses ('>’ means longer fatigue life, '<’ means shorter fatigue life). 